\title{
Investigating Students' Perceptions of Cognitive Presence in Relation to Learner Performance in Blended Learning Courses: A Mixed-Methods Approach
}

\author{
Mustapha Almasi and Chang Zhu \\ Vrije Universiteit Brussel, Pleinlaan 2, 1050, Ixelles, Brussels, Belgium \\ mustapha.almasi@vub.be \\ chang.zhu@vub.be \\ https://orcid.org/0000-0001-7154-0854 \\ DOI: 10.34190/EJEL.20.18.4.005
}

\begin{abstract}
Cognitive presence sustains the learning community through intellectual discourse. Previous studies have explored cognitive presence using mainly quantitative measures in relation to students' perceived learning. This study adopts a mixed-method approach to investigate students' perception of cognitive presence, its relationship with academic performance, and its manifestation in blended learning courses in selected Tanzanian universities. The study adds empirical evidence about the emerging blended learning courses. A total of 351 students were involved in the study. The findings show that students reported a high cognitive presence (mean $=3.9, \mathrm{SD}=.51$ ). Furthermore, cognitive presence predicted student performance. Qualitative data show that students explored information through interaction in group discussions and presentations, with the main push being questions from instructors (teaching presence). Students integrated and applied their knowledge by discussing among themselves, teaching others, and practicing what they had learned. Nevertheless, lack of prompts for feedback, time constraints and lack of confidence were linked with low levels of cognitive presence. The study concludes that students experience high cognitive presence, which predicts their academic performance. The findings imply that cognitive presence tends to influence student performance, regardless of the varying levels of its manifestation.
\end{abstract}

Keywords: cognitive presence, student performance, blended learning, cognitive presence scale, community of inquiry.

\section{Introduction}

Establishing and maintaining a cognitive presence in blended learning (BL) communities is an area that is in great need of research (Garrison and Vaughan, 2008). This is due to the persisting question as to whether students in BL courses can achieve higher levels of cognitive presence, which are important in the learning process (Akyol and Garrison, 2011). While some studies show that blended learning courses have positive effects on students' learning outcomes (Asarta and Schmidt, 2020), it is not clear whether such effects could be linked to cognitive presence alone. Blended learning is a pedagogical approach that combines contact moments with online learning activities and helps to facilitate free and open dialogues among students and instructors (Law, Geng and Li, 2019). In this approach, the best of the traditional face-to-face learning is combined with the best of online instruction, consequently improving interactions between student and student, student and instructor, and student and content, in a way which maximises learning (Dziuban, Hartman and Moskal, 2004). Cognitive presence is defined as a student's ability to construct meaning through discussion and collaboration in the learning community (Chen, Lei and Cheng, 2019). Cognitive presence involves states of puzzlement, information exchange, connection of ideas, creation of concepts, and the testing of the viability of solutions (Garrison and Vaughan, 2008). It is defined in terms of a cycle of practical inquiry where participants move deliberately from understanding the problem or issue through to exploration, integration and application (Garrison, 2017).

Studying perceptions of an object or event has been an important part of research for many years. How people perceive an object or event influences how they approach it. Perception is defined as the interpretation of the world around us using our senses (Alan and Gary, 2011). It is affected by the perceiver's emotions, experiences and needs, as well as the situation and the perceived target (Alan and Gary, 2011). For instance, some students on a BL course may perceive the course differently (the target) due to their needs, emotions or the experiences they have, or even the learning environment in which they study. In this paper, perception is defined as the actual views students have regarding the BL courses they are on and how they approach the courses in accordance with such views. 
The use of a blended approach brings some challenges in the way students interact and how their cognitive presence manifests. Although students on a $\mathrm{BL}$ course need to be able to construct meaning and share knowledge that may enhance their learning, this is not always the case, as some studies indicate (Almasi, Zhu and Machumu, 2018; Akyol and Garrison, 2008). Most studies on cognitive presence and students' performance were done on online courses utilizing either quantitative or qualitative measures using mainly perceived learning (Akyol and Garrison, 2011; Shea, Li and Picket, 2006). While online learning is limited in terms of how students feel connected to and engage in learning, BL offers an opportunity for students and instructors to have contact in both face-to-face and online sessions, thus increase teaching, cognitive and social presences. In turn, this influences students' learning and achievement (Kyleigh, 2017). Following the introduction of BL courses, especially in the Tanzanian context where BL is still emerging, studying cognitive presence and how it relates to student learning is paramount. This is because cognitive presence plays a big role in sustaining learning (Garrison, Anderson and Archer, 1999; Garrison and Vaughan, 2008). This study explores cognitive presence among BL students using a combination of qualitative data through focus group discussions and quantitative data using a cognitive presence scale. The study also links students' perceptions of cognitive presence with their academic performance, thus providing empirical evidence on cognitive presence and student performance in emerging BL courses. The study was conducted in two Tanzanian universities, Mzumbe University (MU), and Dar Es Salaam University College of Education (DUCE). In these universities, blended learning included face-to-face teaching accompanied with student group presentations and supported by instruction on the Moodle platform in the form of assignments, online tests and chats, videos, and social media interactions among students.

Cognitive presence goes to the heart of a community of inquiry (Garrison and Vaughan, 2008). Anderson et al. (2000) argue that cognitive presence by itself is not enough to sustain a critical community of learners. The authors suppose that such an educational community is cultivated within the broader social-emotional environment of the communicative transaction, and that teaching presence, i.e., course design, direct instruction and facilitation is also required in the process. Cognitive presence is operationalised based on Dewey's reflective thinking, which is based on the practical inquiry model (Garrison, 2007b). In cognitive presence, participants move deliberately from understanding the problem or issue through to exploration, integration and (resolution) application. Cognitive presence indicators can be used to evaluate the quality of inquiry in a discussion forum (Redmond, 2014). According to Redmond (2014), the process of students engaging in critical thinking and deep knowledge can occur through reflective processes. Guided by Garrison and Vaughan's (2008) views, in this study, the authors view cognitive presence as having three main phases: exploration or information exchange, initiated by the triggering event, integration and resolution (application). Garrison and Vaughan (2008) further argue that cognitive presence exists when there is the presence of information (exploration), connection of ideas (integration) and application of ideas (resolution). Therefore, based on this assertion, and for simplicity of analysis, this study combined the triggering event with exploration phases. The phases of cognitive presence are illustrated below.

Triggering event: This is an important phase in terms of involving students as it helps to assess students' state of knowledge. Students generate unintended but productive ideas. This phase initiates the inquiry process through a well-organised activity to ensure full engagement and buy-in from the students.

Exploration: This phase focuses first on understanding the nature of the problem and then searching for relevant information and a possible explanation. Moving beyond the exploration phase has been described as being difficult (Garrison, 2007b).

Integration: This phase moves into a more focused and structured phase of constructing meaning. Decisions are made about the integration of ideas and how order can be created.

Resolution: This is the highest level of cognitive presence, which includes the vicarious application of ideas to real-world testing solutions and defending solutions. It is in this phase that students try to resolve the dilemma, be it in terms of reducing complexity by constructing a meaningful framework or discovering a contextually specific solution.

\subsection{Cognitive presence and learner performance}

Many studies have been conducted on cognitive presence in relation to $B L$ in higher education. Studies on the effect of BL on learner performance show various contradictory results. A study by Kyleigh (2017) on the 
impact of blended learning on social, teaching and cognitive presences and perceived learning made several findings. First, the study did not find any significant difference in cognitive difference based on delivery modes, i.e., blended learning and online delivery. Second, the study found a difference in the community of inquiry between students on BL courses and those on online courses. However, a study by Heckman and Annabi (2005) found written communication, which happens in computer-mediated instruction, to be cognitively rich. Not only was written communication precise and permanent, but also it was open to all participants in a way not always possible in a face-to-face context. The findings of this study resemble those of Chen, Lei and Cheng (2019), who found that teaching presence - in terms of asking students questions - positively affected students' levels of cognitive presence. This implies that instructor facilitation, in terms of prompting responses, has an effect on students' learning. Interestingly, in another study, the findings show that working in an asynchronous text-based environment reduces student cognitive load and the need to rely on memory to process large numbers of facts and ideas (Garrison and Vaughan, 2008). In an interesting study on students' engagement in asynchronous online discussion, Galikyan and Admiraal (2019) found an association between students' levels of cognitive presence and their academic performance. The authors analysed transcripts of the online discussions with regard to the cognitive and interactive dimensions among undergraduate and master's students in an English teaching course. The findings of their study indicate the link between cognitive presence and student performance. Similar findings were made in the study conducted by Kyei-Blankson, Ntuli and Donnelly (2016), who found a link between students' learning and cognitive presence.

In a study by Redmond (2014) that involved pre-service secondary teachers in a blended learning course, the results indicate that, when instructors structure online discussions appropriately, learners can share and document their thinking and reflect on their contributions and the perspectives of others while developing new or deeper knowledge. Akyol and Garrison (2011) used a mixed design to study cognitive presence and learning outcomes in online and BL graduate courses. They analysed transcripts to measure learning outcomes, perceived learning, and students' satisfaction, and used interviews to assess learning processes and outcomes. The results show that students in both online and blended courses reached high levels of cognitive presence and learning outcomes. The results suggest that cognitive presence in a community of inquiry is associated with perceived and actual learning outcomes. The authors further found that almost all students in both courses indicated that they perceived cognitive presence to be strong in the course. Also, most of the students believed that they were able to reach the phases of integration and resolution.

This study contributes to the empirical evidence on how students on BL courses experience cognitive presence, how it manifests, and in turn how it relates to their academic performance. The study is unique in two ways: first, it uses a combination of quantitative data (students' reports of cognitive presence) and qualitative data (focus group discussions), thus adding to the in-depth understanding of cognitive presence; second, the study uses students' actual grade scores as opposed to perceived learning.

The purpose of this study is to examine students' perceptions of cognitive presence in relation to learner performance for BL courses in two higher learning institutions in Tanzania, namely MU and DUCE. The following three research questions were addressed:

1. What are students' perceptions regarding cognitive presence in blended learning courses in selected Tanzanian universities?

2. Do students' perceptions of cognitive presence predict their performance in BL courses in selected Tanzanian universities?

3. How do students manifest various cognitive presence phases in achieving the intended learning outcomes?

\section{Participants and procedure}

Participants of this study were undergraduate students from two universities in Tanzania, namely Mzumbe University (MU) - Main Campus, Mzumbe University - Mbeya Campus, and Dar Es Salaam University College of Education (DUCE), taking courses in BL mode. The universities were selected based on prior information that they offer BL courses. Students involved in the study were selected from a list of courses that were offered in $B L$ mode. The courses were selected after obtaining information from the system administrators or instructors showing courses that contained many BL activities, such as student chats, assignments, and online tests among others. Ethical approval was sought through the relevant authorities and units of the universities. Students were invited to participate in the study by the first author. Participation was voluntary and all the participants 
consented verbally. Furthermore, students were informed that their grade scores would be used for the purpose of the study only, and all participating students agreed.

The mean age was 22.34 ( $S D=2.28, \mathrm{~N}=332$ ). There were 190 male students $(57.2 \%)$ and 141 female $(42.5 \%)$, while one $(.3 \%)$ did not indicate gender. The numbers of students studying various subjects were as follows: Classroom Practical Teaching and Organisation E 110 (33.1\%), Language (LL215) 80 (24.1\%), Development Study (DS112) 54 (16.3\%), History (HI368) 65 (19.6\%) and Introduction to Micro and Macroeconomics 23 (6.9\%). The number of students studying for a Bachelor of Education Languages and Management (BELM) was 34 (10.2\%), for a Bachelor of Education Commerce and Accounts (BECA) was 35 (10.5\%), and for a Bachelor of Education Economics and Mathematics (BEEM) was 41 (12.3\%). Bachelor of Arts with Education (BAEd) students numbered 199 (59.9\%), and Bachelor of Human Resources Management students totaled 23 (6.9\%). Of the participating students, 244 were first years (73.5\%), 23 were second years (6.9\%), and 65 were third years (19.6\%). Regarding students' own ratings of their computer skills, the majority (211) stated they had intermediate skills (63.6\%), followed by novices, who numbered 84 (25.3\%) and, lastly, advanced skills, 37 (11.1\%). The majority of the students were from DUCE $(199,59.9 \%)$, followed by Mzumbe Main Campus (110, 33.1\%), and Mzumbe Mbeya Campus (23, 6.9\%).

Table 1: Independent and dependent variables

\begin{tabular}{|l|l|l|}
\hline Dependent variables & Mean & SD \\
\hline Student performance & 27.6 & 5.4 \\
\hline Cognitive presence & 3.9 & .51 \\
\hline Independent variables & Frequency & Percentage \\
\hline Gender & & \\
\hline Male & 190 & 57.2 \\
\hline Female & 141 & 42.5 \\
\hline Total & $\mathbf{3 3 2}$ & $\mathbf{9 9 . 7}$ \\
\hline ICT skills & & \\
\hline Advanced & 37 & 11.1 \\
\hline Intermediate & 211 & 63.6 \\
\hline Novice & 84 & 25.3 \\
\hline Total & $\mathbf{3 3 2}$ & $\mathbf{1 0 0}$ \\
\hline University & & \\
\hline MU main campus & 110 & 33.1 \\
\hline DUCE & 199 & 59.9 \\
\hline MU Mbeya campus & 23 & 6.9 \\
\hline Total & $\mathbf{3 3 2}$ & $\mathbf{1 0 0}$ \\
\hline
\end{tabular}

\subsection{Context}

This study was conducted in two universities. These universities were selected since they offer courses in BL mode and have learning management systems (LMSs) to offer online learning components. The students involved in the study were those who had studied a BL course at least for one semester. This is because the experiences the participants have with BL provide the basis for studying their perceptions (Grundmeyer, 2012). In the studied BL courses, instructors and students interacted in face-to-face sessions and on the Moodle platform, which allowed chats and discussions. Face-to-face sessions were used for lecturing and group presentations, while the Moodle platform was used for online tests, submission of group and individual assignments, provision of teaching notes, online discussions and sometimes videos.

The courses were taught in one semester, which comprises 14 weeks. Data involving students' performances were obtained from the actual students' assignment scores based on the learning activities assessed by their instructors (coursework). Student performance was assessed slightly differently between Mzumbe University and DUCE. At MU, student coursework involved assignments (written and oral group presentations), tests and individual written assignments, which comprised 50 points in total. At DUCE, coursework was obtained from two tests (each totaling 15 marks), one individual assignment (5 marks) and a seminar (5 marks), making a total of 40 points. Due to this difference, consequently, DUCE coursework was transformed into 50 per cent scores as that of MU by a taking a simple formula $\mathrm{X} / 40=\mathrm{Y} / 50$ ? 


\section{Methodology}

This study adopted a convergent parallel design in which quantitative and qualitative data were collected at the same time and their results compared. This provided a comprehensive and complete understanding of the problem (Creswell and Clark, 2017). Quantitative data were collected using a cognitive presence scale. Qualitative data were obtained through focus group discussions.

\subsection{Data collection methods}

Data were collected using a cognitive presence scale followed by focus group discussions.

\subsubsection{Cognitive presence scale}

A cognitive presence scale was used to collect data on students' reports of cognitive presence. Following permissions offered by class instructors, students were provided with the survey in their classes and were asked to fill it in during the class time. The researchers collected the surveys after the students had completed them. The scale contained 12 items. Students were asked to respond to the survey by indicating numbers on a Likert scale with the range 1 = strongly disagree, 2 = disagree, $3=$ neutral, $4=$ agree, and $5=$ strongly agree. The scale had four main parts: triggering event, exploration, integration and resolution. The scale items included: problems posed increased my interest in course issues; I utilized a variety of information sources to explore problems posed in this course; combining new information helped me answer questions raised in course activities; and I have developed solutions to course problems that can be applied in practice to others. At first students were asked by the first author and two research assistants to fill in the survey. Consent was sought verbally in the class. Most students agreed to take part and filled in the survey. Instructors of the selected courses allowed their students to fill in the survey during class time. The surveys were collected after students had completed them.

\subsubsection{Focus group discussions (FGDs)}

The study used FGDs to obtain in-depth opinions about students' perceptions of cognitive presence. After the students had completed the surveys, the first author asked students to volunteer for an FGD. Then, the first author and research assistants recruited a pool of 15 students who agreed to take part in the FGD. This was done in every university visited. After that, five to seven students were randomly selected for the purpose of maximizing interactions. The first author observed the interactions occurring in the group. Cognitive presence questions addressed the BL mode, i.e., both face-to-face and online instructional experiences. Each discussion lasted one hour and 20 minutes. However, the focus group method is known to obscure individual responses, and it requires a skilled facilitator. To minimize this effect, members sat in a circle with the researcher as the moderator sitting in front. As well as tape-recording the discussion, two assistant moderators took notes. These moderators were trained for two to three days to provide them with the general knowledge of the research topic and the ways to take notes and assist in the data collection.

During the FGD, the researcher introduced the topic. Some ground rules were set to allow students to be free and interact in the discussion in a natural manner. The questions asked were: 1 . How did various questions and problems posed to you increase your interest and curiosity in the course issues? 2. How was your motivation (or lack of it) in terms of exploring content-related issues? What did or did not motivate you? 3. What did you do to explore information and solve problems related to your course? 4 . What did you do to resolve contentrelated questions and appreciate your different perspectives in your course? 5. How did new information, learning activities and reflective discussion help you to answer questions, construct solutions and understand fundamental concepts in the course? 6. How do you test your knowledge (of the course you studied) and apply it in solving problems related to the course and work practice?

\subsection{Data analysis}

Students' reports of cognitive presence, as indicated by the cognitive presence scale made up the quantitative data. All the students' data including their reported cognitive presence and demographics were entered into SPSS. The data were analyzed first by descriptive analysis, followed by regression analysis. First reliability analysis was conducted, then the mean for cognitive presence was obtained.

Qualitative data were obtained from focus group responses. Questions on how students presented themselves in the group discussions, social media and/or Moodle were asked. A complete message (paragraph) was used as a unit of analysis, as proposed by Charmaz (2006). The qualitative data were coded using a thematic 
approach (Charmaz, 2006) in NVivo version 12. Two types of code were used: free codes and codes related to the theoretical grounds of the cognitive presence. Focus group questions were set in relation to the concept of cognitive presence, as in Garrison, Anderson and Archer (1999). The FGD transcripts were reviewed time and time again for messages that repeated regularly. The researchers highlighted the quotes and phrases back and forth in search of distinct categories using the constant comparative method (Zhang and Wildemuth, 2009). This method highlights original insights and assists in making differences between groupings apparent (Zhang and Wildemuth, 2009). The coded FGD transcripts were brought together and were checked for relationships within and across data sources. A table was developed for comparing various coded transcripts. Finally, the FGD data were tested against the mental models (cognitive presence indicators) and we ultimately integrated and refined the scripts.

\subsection{Validity and reliability}

The findings show that the scale was reliable (Cronbach's alpha $=.771$, which is acceptable). For the qualitative data, the authors audio-taped the FGDs and interviews to capture every piece of information provided by the participants. The validity of the content was ensured by asking students to provide concrete examples of their explanations of concepts, making use of information sources and having more focus group discussions. Again, field notes were collected as a supporting data source. The notes were formulated as recommended by Bodgan and Biklen (1982). On the first page the date, time and title of the topic covered were recorded. The topic addressed in each discussion and observations about the participants' attitudes were recorded. Direct quotes catching the attention of the researcher were also recorded. All sessions were audio-recorded with the permission of the participants. The researchers neutralized any bias by first acknowledging that their background could influence the interpretation of the data. Therefore, the researchers peer-checked validity by asking some of the participants to review the transcribed notes and included relevant quotes from participants to substantiate the findings (Grundmeyer, 2012).

\section{Findings}

\subsection{Student perceptions of cognitive presence}

The first objective was to quantitatively examine the perception of cognitive presence among students. The cognitive presence scale contained statements ranging from $1=$ strongly disagree to $5=$ strongly agree. From the findings, students reported a high cognitive presence (mean $=3.9, \mathrm{SD}=.51$ ). This means that students experienced a high cognitive presence in the studied BL courses. Among the cognitive presence aspects, integration (mean $=4.1, \mathrm{SD}=.88$ ) was highly reported, followed by resolution/application $($ mean $=3.8, \mathrm{SD}=$ .93 ) and, lastly, exploration (mean $=3.7, \mathrm{SD}=.96$ ).

\subsection{Cognitive presence and performance}

The second objective of the study was to examine whether students' reported cognitive presence predicted their academic performance. First, the researchers examined the mean average of student performance and found it to be 27.6 (SD = 5.4), indicating that the majority of students performed above average (the scores were measured out of 50). Then, regression analysis followed. The results of the regression analysis show that cognitive presence significantly predicted student performance scores: $\beta=14.717, t(6.678)=5.9, p<.001$. Cognitive presence also explained a significant proportion of variance in student performance scores, $R^{2}=$ .096, $F(1,329)=35.03, p<.001$ (see table 2).

Table 2: Cognitive presence and student performance

\begin{tabular}{lllll}
\hline Variable & Unstandardized B & Standardized Coefficients beta & t & sig \\
\hline Constant & 14.717 & & 6.678 & .000 \\
Cognitive presence & 3.296 & .310 & 5.91 & .000 \\
R square & .096 & F value & 35.03 & .000 \\
\hline
\end{tabular}

Predictor (constant): cognitive presence. Dependent variable: student performance

\subsection{How students manifest cognitive presence in BL courses}

As described in Garrison and Vaughan (2008) and in the context of this study, cognitive presence comprises exploration, which is characterized by a sense of puzzlement and information exchange, integration, in which students connect ideas, and resolution (application), where students apply what they have learned. 
The third objective of the study was to explore how students manifest various cognitive presence phases in achieving the intended learning outcomes. In the FGDs, six main questions were asked; the first four questions were about exploration/information exchange (questions 1-4), question 5 was on integration, and question 6 was on resolution/application. Regarding exploration, the researchers wanted to know how various questions and problems raised in the course stimulated student interest and curiosity. Qualitative analysis shows that questions provided by the teacher (teaching presence) stimulated students to interact with each other by forming discussion groups and doing group presentations. Students developed courage through group presentations since they had a sense of "being assessed" by the instructor and fellow students. Further, curiosity and interest increased after knowing that the topics they learned about were related to their work. Students in the field of education cited examples of concepts like classroom management, teacher and student relationships, and learner levels of knowledge as some of the work-related concepts that aroused their interest. Therefore, teaching presence in the form of tutorial questions influenced students' cognitive presence by making them explore various things. The questions (learning tasks) acted as triggering events (Garrison, Anderson and Archer, 1999).

The second aspect of exploration was motivation. The researchers explored student motivation or lack of it. From the qualitative results, students mentioned that they are motivated by five things: first, the thought of what they will do (immediately) after the end of course semester, e.g. teaching practice, and second, fear of not knowing. The fact that they must do teaching practice motivated them to learn and understand the course. They also feared that if they leave the university without the knowledge of what they must do, they may have difficulties in their work settings. The third motive was the students they had to teach. On this, the representative quote is:

"Two things motivate me: first, I know I have to go and do teaching practice; therefore, I need to know. Second, I think about my students in the village; they have inspired me to learn so as I can go and support them." MSD1, Education.

Course content and how the courses were taught was the fourth motive. Students in education learned how to manage a class, teach students and how to interact with them, while students in economics were learning things related to needs and wants, budgeting, and economic planning, which were all practice-oriented or provided content related to daily life. Such topics seemed to motivate students. Economics students mentioned these in the FGD:

"The approach used by the instructor in teaching motivated us a lot. Topics like elasticity of demand; in this topic, we were taught what is necessary and what is not necessary to buy, that is to live in the economic budget. There are goods to buy for luxury and those for necessity: needs and wants." FGD, Economics

The use of a BL approach also motivated students in these courses. The fifth motive was competition and comparison with other students. This was connected to the notion of working in groups. This was especially true when students had to do oral presentations before others and had to discuss topics among themselves.

"What motivates me in this course is the group presentation session where I can compete and compare with others who do well." RESP, Education.

This kind of motivation is what is referred to as achievement or competitive motivation. Positive information about the course obtained from senior students and discussions in groups also motivated students. On the contrary, some students were demotivated by the short time given to do group presentations, lack of prompt feedback and clear course information, length of the topic or teaching notes, instructors' prominent use of English language in class, and what they called "students with low confidence" during presentations. On the length of teaching notes, students in economics remarked:

"I felt demotivated by the length of teaching notes. There were too many slides, 102 slides per topic." FGD, Economics 
For the third aspect of exploration, the researchers inquired what students did to explore information and solve problems. The qualitative analysis shows that students obtained information from six main sources: class group presentations, class leaders, the internet, work from different groups (after group presentations), senior students, and the library. Studies have shown that students often spend so much time in search of information that they fail to reach other high phases of cognitive presence (Kovanović et al., 2016).

The fourth and final aspect of exploration was how students resolved content-related issues. The findings show that students resolved issues using either personal or group-based strategies. Personal strategies, which were mostly used by economics students, included seeking training from the instructors, solving questions individually, sitting in the front of class and listening attentively, visiting the internet (YouTube), reading different books, and studying previous topics before starting new ones (because they believed the topics were interconnected). This is how economics students responded:

"I used to sit in front and to listen carefully, teach fellow students. I visited different books concerning economics matters. Also, I decided to buy a smartphone to acquire soft copy materials. Also watching YouTube economics videos." FGD, Economics.

The second strategy, discussion group (both offline and online) was the most prominent way of resolving such issues and appreciating other students' views. Students on education courses mostly preferred this strategy. Students also taught and guided each other. Interestingly, students were very systematic about how they resolved various issues. First, they would ask everyone to look for a solution (internet search, books, etc.), bring the reference, then meet as a group, share their findings, and finally make a conclusion about what they had found. Students also visited the library and the internet to obtain solutions, and sometimes reviewed questions and answers on certain disputed topics. Interestingly, other similar courses were used as a source of information and learning, e.g. students in education got some insights from other teaching method courses.

"John (a friend) told me, make sure you include diagrams when answering economics questions" ... "I used to ask friends and to get help through online discussion and discussion with friends and my brother. He used to teach/guide me in WhatsApp. Economics is about rules, he told me." FGD, Education

The second phase of cognitive presence is integration. This was covered by question 5 (how new information, learning activities and reflective discussions helped students to answer questions and construct solutions in the course). Analysis of the qualitative data shows that there was a lack of integration in the education courses in general. This was highlighted by the students in the focus groups who mentioned that, despite having done one/two assignments and group presentations, there was still a lot of content that the students felt they were not aware of. Students stated:

"We have noted that some of these activities (especially group presentations), do not make us achieve the intended learning outcomes. This is because we cannot collect all the works presented by other students for review, and we lack prompt feedback from the instructor." FGD, Education.

The quoted statement shows that integration has not been easily achieved in the studied course. In this case, lack of prompt feedback and student failure to obtain some of the learning materials were to blame. Differently, students in economics were able to solve various problems using the knowledge they obtained in their course. New information obtained through peer teaching (involving friends and relatives) and student self-teaching were useful in helping students to answer questions in examinations. The difference in the level of integration between economics and education students is explained by the fact that economics students who faced difficulties used to seek help from friends and relatives who had done the courses before. Some used to visit several books and the internet and, in turn, taught others as a means of learning. In the FGD, a student who spoke with very high enthusiasm remarked:

"A friend told me, make sure you include diagrams when answering economics questions. Every time I did exams, I would include a diagram, and this helped me to score good marks."

Another student remarked: 
"I had a friend from BAF3 (third year students) called Rich (not his real name). He helped me recognize various concepts in economics. He told me the concepts are not hard. I used to find economic concepts hard. (She kept repeating this several times when talking). He used to teach me, and this helped me much in understanding and answering exam questions." FGD, Economics

The last phase of cognitive presence is resolution. This is the highest phase, in which students try to resolve the dilemma and test their knowledge by applying it (Garrison and Vaughan, 2008). Remarkably, the education students mentioned that they would or do test their knowledge through application during teaching practice. They admitted that they had learned useful things in their daily and work-related life, such as microteaching, preparation of scheme of work, use of log books and class management among others, yet they had not had a chance to apply their knowledge during the semester (about 10 weeks after the semester started). However, students in economics claimed to have reached the resolution phase very well.

"The course has made me control wants and needs. I used to buy things when I hear about the promotion. You would hear, for instance, a phone is on promotion and is sold at Tshs 365,000. But when you think, you find out it was 385,000 and that the promotion is only 20,000 less! After this course, I never bought things because of a promotion. I managed to start my own business." FGD, Economics

Interestingly, other students tested their knowledge by teaching others and practicing what they had learned. Some depended on the teacher to resolve some difficulties in the lesson. Some of the students mentioned having increased their confidence due to what they had learned in these courses.

"I learned how to budget my expenditures. Also, I am not frustrated when economic situations are not good. For instance, I know when the circulation of money is high in the public, i.e., the Bank of Tanzania will do something with the commercial banks to pull the money from people." FGD, Economics

\section{Discussion of findings}

This study investigated students' perceptions of cognitive presence in BL courses in three Tanzanian universities using a mixed method. The study quantitively compared how students rated their cognitive presence compared with their academic performance and traced how they reached various phases of cognitive presence through qualitative analysis.

\subsection{Perception of cognitive presence}

The first objective of the study was to examine students' perceptions of cognitive presence. The study shows that students reported a high cognitive presence, as indicated by the mean score of $3.9(\mathrm{SD}=.51)$. Previous studies, such as Almasi and Zhu (2017), Akyol and Garrison (2008), and Akyol and Garrison (2011) also found high cognitive presences. In the current study, the aspect of integration was highly rated (mean $=4.1)$ while application (mean $=3.8$ ) and exploration (mean $=3.7$ ) were almost equally valued. Garrison and Akyol (2008), Almasi and Zhu (2017) and Gašević et al. (2015) also found integration to be the most reported aspect of cognitive presence. A study by Kovanović et al. (2016) found exploration to be highest, and resolution to be the lowest.

Interestingly, while students rated integration as high in the survey, in the FGDs they indicated that was not the case, especially for education students. This means, possibly, students rated a value high in the survey but cannot explain why. Several studies have shown that resolution (application) is not easy to achieve (Kovanović et al., 2016; Garrison, Anderson, and Archer, 2010; Garrison, Anderson and Archer, 2001).

\subsection{Cognitive presence and student performance}

The second objective of the study was to examine cognitive presence in relation to student performance. The findings show that cognitive presence significantly predicted student performance scores: $\beta=14.717, t(6.678)$ $=5.9, p<.001$. This means that cognitive presence influences student performance. The more students engage in cognitive discourse, the more it influences their performance. These findings contradict our previous findings (Almasi, Zhu and Machumu, 2008; Almasi and Zhu 2017), but support other findings, such as those of Akyol and Garrison (2008; 2011), who used perceived learning as opposed to actual outcomes. In a study by 
Szeto (2014), students stated that they learned the course knowledge and skills quickly and easily through the assessment tasks. This means they associated their cognitive presence with assessment tasks. In the current study, the assessment tasks that generated coursework were more related to what students were learning, possibly explaining the connection between cognitive presence and student performance.

\subsection{How students manifest cognitive presence in BL courses}

This study has approached cognitive presence in three phases, explicated in the community of inquiry model: exploration, which is characterized by a sense of puzzlement and information exchange; integration, in which students connect ideas; and resolution, which is the application of the idea.

The third objective of the study was to explore how students manifest various cognitive presence phases in achieving the intended learning outcomes. The results of the qualitative data explain how students showed various phases of cognitive presence. In all three universities, students expressed all the phases of cognitive presence. They managed to explore information through interaction with other students in independent group discussions and oral group presentations. The main push behind the exploration was the questions provided by the instructors (teaching presence). Consistent with the theoretical foundation in Anderson et al. (2000), teaching presence in the forms of questions and learning tasks prompted cognitive presence. Interestingly, practice, fear of failure or not knowing, competition among themselves, nature of the course content, acquisition of useful daily or work-related knowledge, and regard for others were the main motivations for their exploration.

This means students explored more course content because they would need to practice in the field, or because they wanted to compete and compare (competitive/achievement motivation) and that they had people who would benefit from their knowledge. Achievement motivation is the desire to meet some internal standards of excellence, which involves a competitive component and wanting to excel compared with others in terms of mastering. Students solved course-related problems by exploring various sources such as the internet and the library, and by asking senior students. Other similar courses were used as a source of information and learning, e.g. students in practical teaching got some insights from teaching method courses (e.g. commerce teaching method). Some students depended on the teacher to resolve some difficulties in the lesson.

When the qualitative and quantitative findings are compared, this study finds that students gave a high value to the integration phase of cognitive presence in the survey. This may be due to various forms of bias, such as social desirability, extreme responding or acceptance bias (Furnham, 1986). This means respondents tend to give responses that are desirable to the researcher, choose extreme points of the scale, or tend to go for the agree responses due to various reasons. However, in the FGDs, many students (mostly education) indicated that they could not achieve integration. This failure was associated with reasons such as lack of prompt feedback and lack of clear course information, instructors' prominent use of English language in class (mentioned by economics students only), and lack of competence during class presentations. In a study by Akyol and Garrison (2011), time was identified as a barrier for students to reach a higher cognitive level of resolution. The length of the course was not enough for students to put into action what they had learned.

Kovanović et al. (2016) offer a psychological explanation for students' failure to reach higher order thinking. They argue that students spend more time searching for information and hypothesising before they get to apply what they learn. Interestingly, similar explanations were offered by students in the studied BL courses (especially education students), who mentioned that they did not get time to practice what they had learned, instead spending time visiting the library, doing internet searches and collecting works of other presentation groups. Meanwhile, students in the studied courses were able to apply and test their knowledge (resolution) by teaching fellow students, practice what they had learned, and compare what they read over the internet with the knowledge bases they obtained from books, classes and their own experience. Comparatively, a study by Garrison Anderson and Archer, (2010) mentions failure to reach integration and resolution phases due to the design of the course and learning expectations. Nevertheless, in this study, some students showed concern about lack of authenticity in terms of what they read over the internet, so they checked their knowledge against the books and the instructors' face-to-face tutorials. 


\section{Conclusion, implications and limitations of the study}

This study explored the perception of cognitive presence among students studying blended learning courses in relation to their performance in Tanzanian universities. Based on the findings, the following conclusions can be made. First, based on the survey, students in the studied BL courses reported a high level of cognitive presence. Second, our study finds that students' perceived cognitive presence tends to predict their academic performance. This means cognitive presence influences student academic performance. This finding is explained by the fact that, when a blended learning course is well integrated, and when the tasks given to students are related to the assessments done, there tends to be a link between cognitive presence and student performance scores.

Third, students experience various levels of cognitive presence, which were triggered mostly by the teaching presence (questions and learning tasks supplied by the instructor). In the exploration phase, questions raised by the instructors stimulated curiosity and interest in the course. Students were motivated by the feeling of practicing what they had learned, the nature of the course content, competitions among themselves, and the use of the BL approach (the use of learning). In the same respect, students used various sources for exploration of content-related issues. Such sources included student leaders, study groups, the internet, and the library and senior students. Furthermore, students resolved content-related issues using either personal or group-based strategies, or a combination of both.

Among the cognitive presence aspects, integration is highly reported in the surveys; however, in general, students were able to reach all the phases of cognitive presence (exploration, integration and resolution), though at varying degrees between education and economics students. Though both education and economics students mentioned having reached the phases of cognitive presence, students in economics seemed to experience the highest two levels of cognitive presence (integration and resolution) more than their education counterparts. The fact that the content they learned had a day-to-day practical significance or they were able to practice what they had learned made students reach the resolution phase.

This study is limited in the following ways. First, the sample is limited to only two universities in the country, despite there being more than 40 higher learning institutions in Tanzania; thus, limiting the study to two universities may hinder the generalization of the findings. Second, our study involved only two degree programs, education and economics. Both these courses belong to the realm of social sciences; there could possibly be differences in the perception of cognitive presence in the soft and the hard disciplines. Therefore, it would be interesting for future studies to involve both hard and soft disciplines. Furthermore, the study used a self-rating survey to measure students' reporting of cognitive presence, thereby exposing the study to selfreporting bias. However, data from the focus group discussions were used to complement and offer a deeper insight into cognitive presence.

Nevertheless, the findings of this study imply that high cognitive presence tends to influence student academic performance. They also imply that, when there is a link between student learning activities and the assessments they do, cognitive presence tends to be related to their academic performance. The study also implies that BL courses taught in Tanzanian universities have the potential to make students reach various phases of cognitive presence. The fact that students in some courses could not reach all the phases of cognitive presence calls for the course designers to continue improve their courses in way that enhances the learning of students.

\section{References}

Akyol, Z. and Garrison, D.R., 2008. The development of a community of inquiry over time in an online course: Understanding the progression and integration of social, cognitive and teaching presence. Journal of Asynchronous Learning Networks, 12, pp.3-22. Available at: https://eric.ed.gov/?id=EJ837483. [Accessed on 20 January 2020]

Akyol, Z. and Garrison, D.R., 2011. Understanding cognitive presence in an online and blended community of inquiry: Assessing outcomes and processes for deep approaches to learning. British Journal of Educational Technology, 42(2), pp.233-250. Available at: https://onlinelibrary.wiley.com/doi/full/10.1111/j.1467-8535.2009.01029.x [Accessed on 22 January 2020]

Alan, S. and Gary, J., 2011. Perception, attribution, and judgment of others. Organizational behaviour: Understanding and managing life at work, Upper Saddle River. Pearson Education 7, pp.1-20. 
Almasi, M., Zhu, C. and Machumu, H., 2018. Teaching, social, and cognitive presences and their relations to students' characteristics and academic performance in blended learning courses in a Tanzanian University. Afrika Focus, 31(1), pp. 51-71

Asarta, C. J. and Schmidt, J. R. 2020. The effects of online and blended experience on outcomes in a blended learning environment', Internet and Higher Education, 44 (January 2018), pp. 100708. doi: 10.1016/j.iheduc.2019.100708. Available at: https://www.sciencedirect.com/science/article/pii/S1096751619304269 [Accessed on 22 January 2020]

Garrison, D.R., Anderson, T. and Archer, W., 1999. Critical inquiry in a text-based environment: Computer conferencing in higher education. The internet and higher education, 2(2-3), pp.87-105. Available at: https://www.sciencedirect.com/science/article/pii/S1096751600000166 [Accessed on 22 January 2020]

Bogdan, R., C and Sari Knopp Biklen. 1982. Qualitative Research for Education: An Introduction to Theory and Methods .Boston. Allyn and Bacon. Inc. USA.

Chen, Y., Lei, J. and Cheng, J. 2019. What if online students take on the responsibility: Students' cognitive presence and peer facilitation techniques', Online Learning Journal, 23(1), pp. 37-61. doi: 10.24059/olj.v23i1.1348. Available at: https://eric.ed.gov/?id=EJ1210949. [Accessed on 23 January 2020]

Creswell, J.W. and Clark, V.L.P., 2017. Designing and conducting mixed methods research. Los Angeles. Sage publications.

Dziuban, C.D., Hartman, J.L. and Moskal, P.D., 2004. Blended learning. EDUCAUSE Center for Applied Research Bulletin, 7(1), p.12. Available at: https://www.educause.edu/ /media/files/library/2004/3/erb0407pdf.pdf?la=en. [Accessed January 13 2020]

Galikyan, I. and Admiraal, W. 2019 Students' engagement in asynchronous online discussion: The relationship between cognitive presence, learner prominence, and academic performance, Internet and Higher Education. Elsevier, 43(July), p. 100692. doi: 10.1016/j.iheduc.2019.100692. Available at: https://www.sciencedirect.com/science/article/pii/S1096751619304105. [Accessed on January 232020 ]

Garrison, D.R., 2007. Online community of inquiry review: Social, cognitive, and teaching presence issues. Journal of Asynchronous Learning Networks, 11(1), pp.61-72. Available at: https://eric.ed.gov/?id=EJ842688 [Accessed on January 23 2020]

Garrison, D. R. 2017. Cognitive presence and critical thinking. Available at: http://www.thecommunityofinquiry.org/editorial5 [Accessed on January 232020 ]

Garrison, D.R. and Vaughan, N.D., 2008. Blended learning in higher education: Framework, principles, and guidelines. San Francisco. John Wiley \& Sons.

Garrison, D. R., Anderson, T., and Archer, W. 2001. Critical thinking, cognitive presence, and computer conferencing in distance education. American Journal of distance education, 15(1), pp. 7-23. Available at :https://www.tandfonline.com/doi/abs/10.1080/08923640109527071. [Accessed on January 20 2020]

Garrison, D.R., Anderson, T. and Archer, W., 2010. The first decade of the community of inquiry framework: A retrospective. The internet and higher education, 13(1-2), pp.5-9. Available at: https://www.sciencedirect.com/science/article/pii/S1096751609000608 [Accessed on January 23 2020]

Gašević, D., Adesope, O., Joksimović, S. and Kovanović, V., 2015. Externally-facilitated regulation scaffolding and role assignment to develop cognitive presence in asynchronous online discussions. The internet and higher education, 24 , pp.53-65. Available at: https://www.sciencedirect.com/science/article/pii/S1096751614000700 [Accessed on January $232020]$

Grundmeyer, T.A., 2012. A qualitative study of the perceptions of first year college students regarding technology and college readiness. Graduate Theses and Dissertations 12599. Available at: https://lib.dr.iastate.edu/etd/12599/ [Accessed on January 23 2020]

Harrell, Kyleigh. 2017. The Impact of Blended Learning on Social Presence, Cognitive Presence, Teaching Presence, and Perceived Learning. Available at: https://digitalcommons.liberty.edu/cgi/viewcontent.cgi?article=2469\&context=doctoral Accessed on January 23, 2020]

Heckman, R. and Annabi, H., 2005. A content analytic comparison of learning processes in online and face-to-face case study discussions. Journal of Computer-Mediated Communication, 10(2), pp. JCMC10210. Available at: https://academic.oup.com/jcmc/article/10/2/JCMC10210/4614463 [Accessed on January 23 2020]

Kovanović, V., Joksimović, S., Waters, Z., Gašević, D., Kitto, K., Hatala, M. and Siemens, G., 2016. April. Towards automated content analysis of discussion transcripts: A cognitive presence case. In Proceedings of the sixth international conference on learning analytics \& knowledge (pp. 15-24). ACM. Available at: https://dl.acm.org/doi/abs/10.1145/2883851.2883950 [Accessed on January 23 2020]

Kyei-Blankson, L., Ntuli, E. and Donnelly, H. 2016. Establishing the Importance of Interaction and Presence to Student Learning in Online Environments', World Journal of Educational Research, 3(1), p. 48. doi: 10.22158/wjer.v3n1p48. Available at: https://pdfs.semanticscholar.org/0692/24e7493f9009ff283e8184567a640068a2d1.pdf [Accessed on January 23 2020]

Law, K. M. Y., Geng, S. and Li, T. 2019. Student enrollment, motivation and learning performance in a blended learning environment: The mediating effects of social, teaching, and cognitive presence', Computers and Education. Elsevier, 136(February), pp. 1-12. doi: 10.1016/j.compedu.2019.02.021. Available at: https://www.sciencedirect.com/science/article/pii/S0360131519300508 [Accessed on January 23 2020]

Redmond, P., 2014. Reflection as an indicator of cognitive presence. E-Learning and Digital Media, 11(1), pp.46-58. Available at: https://journals.sagepub.com/doi/10.2304/elea.2014.11.1.46 [Accessed on January 23 2020] 
Shea, P., Li, C.S. and Pickett, A., 2006. A study of teaching presence and student sense of learning community in fully online and web-enhanced college courses. The Internet and Higher Education, 9(3), pp.175-190. Available at: https://www.sciencedirect.com/science/article/pii/S1096751606000364 [Accessed on January 23 2020]

Szeto, E., 2015. Community of Inquiry as an instructional approach: What effects of teaching, social and cognitive presences are there in blended synchronous learning and teaching? Computers Education, 81, pp.191-201. Available at: https://www.sciencedirect.com/science/article/pii/S0360131514002358 [Accessed on January 23 2020]

Vaughan, N. and Garrison, D.R., 2005. Creating cognitive presence in a blended faculty development community. The Internet and higher education, 8(1), pp.1-12. Available at: https://www.sciencedirect.com/science/article/pii/S1096751604000764 [Accessed on January 23 2020]

Zhang, Y., and Wildemuth, B. M.2009. Qualitative analysis of content. Applications of social research methods to questions in information and library science, 308, p. 319 